\title{
A Novel Effect for Glycine on Root System Growth of Habanero Pepper
}

\author{
Ángel V. Domínguez-May',2, Mildred Carrillo-Pech ${ }^{1,2}$, Felipe A. Barredo-Pool ${ }^{3}$, \\ Manuel Martínez-Estévez ${ }^{2}$, Rosa Y. Us-Camas ${ }^{2}$, Oscar A. Moreno-Valenzuela², \\ and Ileana Echevarría-Machado ${ }^{2,4}$ \\ Centro de Investigación Científica de Yucatan (CICY), Calle 43 \# 130, Col. Chuburna de Hidalgo, \\ Merida, Yucatan, 97200, Mexico
}

\begin{abstract}
AdDitional INDEX wORDs. amino acids, root anatomy, root growth, root hairs, starch grains
Abstract. Amino acids, a major fraction of the low-molecular-weight organic nitrogen in soil, act as signaling molecules that indicate the presence of nutrient-rich patches to the roots. To characterize the effects of amino acids on root growth, we used seedlings of habanero pepper (Capsicum chinense), one of the most widely cultivated annual spice crops in the world. We tested the effect of $L$-glutamate, $L$-aspartate, and glycine on the primary root of seedlings grown aseptically under different conditions of $\mathrm{pH}$ and light. L-glutamate and L-aspartate did not inhibit the root growth of habanero pepper. In contrast, glycine inhibited the growth of roots, stimulated root hair growth, and induced a significant accumulation of starch grains in the root apex. The use of aminoethoxyvinylglycine, an inhibitor of ethylene biosynthesis, and the evaluation of 1-aminocyclopropane-1-carboxylic acid oxidase expression provided evidence of a role for ethylene in the root responses to glycine. We suggest that these changes in the root apex in response to exogenous glycine could be an important adaptive response that allows plants to efficiently access the fluctuating availability of nutrients in the soil.
\end{abstract}

It is known that low nutrient availability restricts plant growth in many environments, especially in places that are extremely poor in nutrients such as the tropics (Dakora and Phillips, 2002). Nutrient availability in soil fluctuates unpredictably and can change several orders of magnitude over a distance of centimeters or the course of hours (Hodge, 2004). In terrestrial plants, roots are the organs that sense and acquire nutrients in the soil.

In plants, nitrogen is the mineral nutrient that is required in the largest quantities and represents up to $2 \%$ of plant dry matter. As a result of its important role in metabolism, the availability of nitrogen $(\mathrm{N})$ is one of the key factors that limits crop productivity (Masclaux-Daubresse et al., 2010). Nitrate is the major source of $\mathrm{N}$ for plants in agricultural soil; therefore, most studies of root plasticity in response to $\mathrm{N}$ have been performed using this inorganic $\mathrm{N}$ source (reviewed by Alvarez et al., 2012).

Amino acids represent a major fraction of the low-molecularweight organic $\mathrm{N}$ that is dissolved in the soil (Jones et al., 2005). The presence and concentrations of different amino acids vary greatly from one ecosystem to another. In general, these compounds are found at low concentrations in the soil, $\approx 0.01$ to $10 \mu \mathrm{M}$ (Jones et al., 2005), but their levels reach millimolar levels in patches with decomposing organic matter (Öhlund and

Received for publication 15 July 2013. Accepted for publication 18 Sept. 2013. This work was supported by the Consejo Nacional de Ciencia y Tecnología, CONACYT (Project 169041), and CONACYT fellowships to Angel V. Domínguez-May (213547) and Rosa Y. Us-Camas (300631).

We thank Miriam Monforte González for their kind contribution in work with images processing in Adobe Photoshop CS5 program. We thank Jose Juan Zúniga for specific primers to amplify $A C C$ oxidase.

${ }^{1}$ The first two authors (A.V.D.-M. and M.C.-P.) contributed equally to this work and should be considered co-first authors.

${ }^{2}$ These authors are in Unidad de Bioquímica y Biología Molecular de Plantas at CICY.

${ }^{3}$ This author is in Unidad de Biotecnología at CICY.

${ }^{4}$ Corresponding author. E-mail: ileana@cicy.mx.
Näsholm, 2004). In these patches, glutamic acid, serine, glycine, alanine, and aspartic acid are the most abundant amino acids (Lipson and Näsholm, 2001).

In addition to their importance as a $\mathrm{N}$ source for some plants in low-N systems (Forsum et al., 2008), it has been recently suggested that amino acids may be sensed in the root tip by specific receptors and act as signaling molecules that indicate the presence of nutrient-rich patches in the soil (Walch-Liu et al., 2006b).

Excised root culture has been used to test amino acids as both potential growth factors and a source of $\mathrm{N}$ for root growth (Harris, 1959; Skinner and Street, 1954; Street et al., 1960). Skinner and Street (1954) reported both positive and negative effects of glycine, L-glutamate, and other amino acids on excised Senecio vulgaris roots. Arginine, but not valine or glycine, was found to be effective as a sole source of $\mathrm{N}$ for the growth of excised Trifolium pratense roots (Harris, 1959). In contrast, arginine supplied as a sole source of $\mathrm{N}$ had no detectable effect on the root growth of isolated oat (Avena sativa) embryos, although valine, serine, tyrosine, isoleucine, leucine, and threonine all reduced the growth of roots in length by more than twothirds (Harris, 1956).

Recent studies of regulatory interactions between amino acids and root growth have been conducted in seedlings of Arabidopsis thaliana (Walch-Liu and Forde, 2008; Walch-Liu et al., 2006a). However, the root response to amino acids is dependent on several factors such as the species, type of amino acid, and their concentration (Harris, 1959; Skinner and Street, 1954; Street et al., 1960; Walch-Liu and Forde, 2008; WalchLiu et al., 2006a). For example, L-glutamate did not significantly change the primary root (PR) growth of Brassica napus, and under certain experimental conditions, it induced an exactly opposite response to that reported in A. thaliana (Leblanc et al., 2008).

The habanero pepper belongs to the genus Capsicum and is cultivated in Yucatan, Mexico, where more than $90 \%$ of these 
soils are lithosols and rendzinas. The soil in this area is mostly clay, shallow, and is characterized by a high organic matter content, alkaline $\mathrm{pH}$, and low inorganic N (Borges-Gómez et al., 2008).

Peppers (Capsicum sp.) are a unique spice used as a basic flavoring and coloring ingredient in many cuisines worldwide that adds tanginess to otherwise bland dishes (Ravishankar et al., 2003). The genus Capsicum is one of the most cultivated annual and spice crops worldwide with a cultivated area of 1.65 million hectares with a global production of 24 million tonnes (Bosland and Votava, 2000).

Similar to any other crop of economic importance, pepper production is affected by abiotic factors such as water and nutrient availability, which diminish the yield and quality of the fruit (Ochoa-Alejo and Ramirez-Malagon, 2001). For example, $\mathrm{N}$ and potassium can directly affect the synthesis of capsaicinoids, the compounds that confer pungency to the pepper fruit (Medina-Lara et al., 2008). No genetic investigation of root response to soil $\mathrm{N}$ has been undertaken in pepper (Wang and Bosland, 2006).

Reports of amino acids affecting the root growth of Solanaceae family members, which include habanero pepper, are scarce and inconclusive, because they present limited data or contradictory effects (Kim et al., 2010; Street et al., 1960; Walch-Liu et al., 2006a).

The objective of this study was to evaluate the effect of amino acids on the PR growth of habanero pepper. We also characterized these effects under $\mathrm{pH}$ and light conditions similar to those previously tested for A. thaliana (Walch-Liu et al., 2006a) and extend this characterization using dark conditions, as roots grow in the soil, and $\mathrm{pH}$ conditions similar to those used for habanero pepper cultivation in Yucatan peninsula soils (Bautista et al., 2005; Borges-Gómez et al., 2008). Given that the glycine-induced phenotype of habanero pepper root was similar to the one observed in ethylene studies (Strader et al., 2010), we evaluated the effect of glycine on the expression levels of 1-aminocyclopropane-1-carboxylic acid (ACC) oxidase, a key enzyme in the ethylene biosynthesis pathway, which has been demonstrated to be a target of transcriptional regulation by nutritional stress and others abiotic deleterious conditions (Lynch and Brown, 1997; Morgan and Drew, 1997). Glycine inhibited cell elongation but not the cell number in the root apex. We suggest that the inhibitory effect of glycine on habanero pepper PR growth is likely the result of augmented ethylene production.

\section{Materials and Methods}

Plant material and growth Conditions. Capsicum chinense 'Orange' was sourced from Seminis Vegetable Seeds (Seminis Vegetable Seeds, St. Louis, MO). Seeds were surfacesterilized (Celis-Arámburo et al., 2011) and germinated by placing them in $9-\mathrm{cm}$ petri dishes containing a thin layer of cotton covered with filter paper moistened with sterile distilled water. The dishes were placed in the dark at $25 \pm 2{ }^{\circ} \mathrm{C}$.

Once the radicle had protruded (after $\approx 5 \mathrm{~d}$ ), the seeds were transferred to 9 -cm petri dishes that were oriented vertically and placed in the dark at $25 \pm 2{ }^{\circ} \mathrm{C}$. The growth medium $(25 \mathrm{~mL}$ per petri dish) contained $23 \mathrm{~mm}$ 2-(N-morpholino)ethanesulfonic acid (MES) (pH 5.7), 0.5\% (w/v) sucrose, 1\% (w/v) agar-agar and B5 salts (Gamborg et al., 1968) (1:50 final dilution) in which $\mathrm{KNO}_{3}$ and $\left(\mathrm{NH}_{4}\right)_{2} \mathrm{SO}_{4}$ were replaced with $1 \mathrm{mM} \mathrm{KCl}$ and $0.5 \mathrm{~mm}$ L-glutamine.
Amino ACID Treatment. Once the roots had developed (4 to $5 \mathrm{~d}$ ), seedlings with a $22 \pm 2 \mathrm{~mm}$-long PR were transferred to treatment dishes (three seedlings per dish) containing the same growth medium, except that amino acids were added. The superior segment of the medium in the dishes was removed so that the aerial portion of the seedling did not contact the medium; only the root was placed on the treatment medium.

To determine the effect of amino acids on root growth, aqueous stock solutions (100 mm) of D-glutamate, L-glutamate, L-aspartate, and glycine were prepared and filtered for sterilization. Aliquots of each solution were separately added to the growth medium ( $\mathrm{pH}$ 5.7) after autoclaving, adjusting the concentration of each amino acid to $1 \mathrm{~mm}$ in the medium. In the control group, $1 \mathrm{~mm} \mathrm{KCl}$ was added to the medium $(2 \mathrm{~mm}$ $\mathrm{KCl}$ total in the medium) instead of amino acids. Another control for the experiment was performed in which L-glutamine was eliminated from the growth medium, and the seedlings were only treated with $1 \mathrm{~mm}$ L-glutamate. Each petri dish was positioned vertically and stored at $25 \pm 2{ }^{\circ} \mathrm{C}$ with a 16-h light $\left(123 \mu \mathrm{mol} \cdot \mathrm{m}^{-2} \cdot \mathrm{s}^{-1}\right)$ and 8 -h dark photoperiod for $4 \mathrm{~d}$. PR growth was recorded at Day 4, and PR length was measured directly on the petri dish with a ruler. This experiment was repeated three times using five petri dishes for each treatment $(n=15$ seedling per treatment). We applied a one-way experimental design using six treatments and one measurement time (PR growth at Day 4 of treatment).

For dose-response experiments, L-glutamate concentrations in the medium were adjusted to $0.25,0.50,0.75,1$, and $5 \mathrm{~mm}$. In all cases, the amount of potassium $(\mathrm{K})$ in the medium was adjusted to $5 \mathrm{~mm}$ by adding $\mathrm{KCl}$, and the control treatment contained $5 \mathrm{~mm} \mathrm{KCl}$ in the medium $(6 \mathrm{~mm} \mathrm{KCl}$ total) instead of L-glutamate. The experiment was carried out in similar conditions as described for the previous experiment $(\mathrm{pH} \mathrm{5.7,}$ 16/8 h light/dark), and PR growth was evaluated on Day 4 of treatment. This experiment was repeated two times using 15 seedlings for each concentration treatment ( 90 seedlings total). Similar to the previous experiment, we applied a one-way experimental design using six concentrations of L-glutamate and one measurement time.

To test the effect of $\mathrm{pH}$ and light conditions on root growth in the presence of amino acids, L-glutamate and glycine treatments were performed at $\mathrm{pH} 7.5$, and the $23 \mathrm{~mm} \mathrm{MES}$ in the medium was replaced with $23 \mathrm{~mm}$ 4-(2-hydroxyethyl)piperazine-1ethanesulfonic acid. Each petri dish (five per treatment; $n=15$ seedlings for each treatment) was positioned vertically to permit root growth, and the dishes were stored at $25 \pm 2{ }^{\circ} \mathrm{C}$ with either a continuously dark or $16 / 8 \mathrm{~h}$ light/dark, depending on the experiment.

Daily PR growth was recorded from Days 0 to 4 at the same hour in which the seedlings were treated. PR length was measured directly on the petri dish with a ruler, and the roots were observed and photographed using a stereoscopic microscope (Leica MZ FLIII; Leica Microsystems, Tokyo, Japan) at the end of the experiment. The data are presented as daily growth rate (centimeters per day) over $4 \mathrm{~d}$ of treatment or the growth accumulated between Days 0 and 4 (centimeters). This experiment was repeated three times with 15 seedlings per treatment. The experimental design was one-way with three treatments $(\mathrm{KCl}, \mathrm{L}$-glutamate, and glycine) and one time (daily growth or accumulated growth) at each $\mathrm{pH}$ condition (5.7 or 7.5 ) or light condition (dark or photoperiod condition). 
Microscopy. Seedlings were cultured under the following treatment conditions ( 15 seedlings for each treatment): $1 \mathrm{~mm}$ $\mathrm{KCl}$ (control), $1 \mathrm{~mm} \mathrm{~L}$-glutamate, or $1 \mathrm{~mm}$ glycine for $3 \mathrm{~d}$ under similar conditions to the previously described experiments $(\mathrm{pH}$ 5.7 and dark conditions). For detailed anatomical studies, we selected three roots from the 15 seedlings in each treatment group that showed average PR growth, taking into account the daily growth results under the same conditions from the previous experiment that were performed in triplicate. Roots were fixed in formalin/acetic acid/ethanol/water [10:5:50:35 (by volume)]. After $48 \mathrm{~h}$ of fixation, the specimens were dehydrated in a graded ethanol series from $30 \%$ to $100 \%(\mathrm{v} / \mathrm{v})$, infiltrated, and embedded in plastic resin (JB-4 glycol methacrylate; Polysciences, Los Angeles, CA).

Longitudinal sections $3 \mu \mathrm{m}$ thick were cut using a microtome (Microm HM 325; Thermo Scientific, Walldorf, Germany) from the root tip. Sections were stained with Schiff reagent as described by McManus (1961) and 7\% (w/v) Naphthol blue black mounted in Permount (SPI5-500; Fisher Scientific, Fair Lawn, NJ), analyzed, and photographed using a microscope (Primo Star; Carl Zeiss, Göttingen, Germany). Images were assembled using Adobe Photoshop CS5 software (Adobe System, San Jose, CA) and these images were used to quantify the length of the root cap and meristematic, transitions, and elongation zones. The cell number and mean cell lengths in the epidermal cell files from each zone and the distance from the root tip to the first root hair were determined using National Institutes of Health (NIH) ImageJ software (Schneider et al., 2012). Three PRs per treatment were processed and these data were confirmed by the images from the cleared roots (five roots per treatment) using the method reported by Dubrovsky et al. (2006).

Serial transverse sections of $3 \mu \mathrm{m}$ were made through $\approx 2330 \mu \mathrm{m}$ of tissue starting from the root tip (three PRs per treatment, selected as described previously for longitudinal sections). Transverse sections were processed in a similar manner to the longitudinal sections, and the radial root diameter was quantified from these images using NIH ImageJ software. We applied a one-way experimental design using three treatments with three repetitions (anatomic sections from three roots).

Transverse sections also were stained with $0.5 \%(\mathrm{w} / \mathrm{v}) \mathrm{I}_{2}-\mathrm{KI}$ (Lugol's iodine staining) for visualization of starch grains by light microscopy as reported by Ponce et al. (2005).

Starch Content. To determine the level of starch, we sampled $8 \mathrm{~mm}$ from the root apex of seedlings (30 seedlings per treatment) treated for $3 \mathrm{~d}$ under a dark condition on $\mathrm{pH} 5.7$ media with $1 \mathrm{~mm}$ glycine or $1 \mathrm{~mm} \mathrm{KCl}$ (control). The extraction and determination of starch were performed as described previously (Rodas-Garcia and Collazo-Ortega, 2006). The experiment was repeated twice. We applied a one-way experimental design using two treatments with two samples (two repetitions) replicated three times $(n=6)$.

TOTAL RNA EXTRACTION AND 1-AMINOCYCLOPROPANE-1CARBOXYLIC ACID OXIDASE GENE EXPRESSION ANALYSIS. We used seedlings grown for $3 \mathrm{~d}$ in the presence of $1 \mathrm{~mm} \mathrm{KCl}$ (control), $1 \mathrm{~mm}$ glycine, or $1 \mathrm{~mm}$ glycine $+1 \mu \mathrm{M}$ aminoethoxyvinylglycine $(\mathrm{AVG})$ in dark conditions and $\mathrm{pH} 5.7$ to evaluate the levels of ACC oxidase gene expression. Total RNA was isolated from $15 \mathrm{PR}$ apices ( $8 \mathrm{~mm}$ from the root apex) from each treatment using an RNeasy Plant Mini Kit (Qiagen, Gaithersburg, MD) and quantified with a spectrophotometer (Nanodrop 2000; Thermo Scientific, Wilmington, DE). For the cDNA synthesis,
400 ng of total RNA was reverse-transcribed using oligo-dT and SuperScript ${ }^{\mathrm{TM}}$ reverse transcriptase (Invitrogen, Carlsbad, CA). Then, $100 \mathrm{ng}$ of cDNA was used in the subsequent quantitative polymerase chain reaction (qPCR). The reactions were performed in a real-time PCR system (StepOne; Applied Biosystems, Foster City, CA) using Platinum SYBR Green qPCR SuperMix-UDG (Invitrogen). The PCR conditions were as follows: 1 cycle at $95^{\circ} \mathrm{C}$ for $5 \mathrm{~min}, 30$ cycles at $94{ }^{\circ} \mathrm{C}$ for $30 \mathrm{~s}, 60^{\circ} \mathrm{C}$ for $30 \mathrm{~s}$, and $72{ }^{\circ} \mathrm{C}$ for $22 \mathrm{~s}$. We used specific primers for an $A C C$ oxidase gene cloned from habanero peppers (AJ879117), which previously were used to evaluate the transcript levels of ACC oxidase (Núñez-Pastrana et al., 2011). The specific primers used for PCR were forward (F): CAT TACGGCCGGGGACATT and reverse (R): TGCTTTC CCAGTCTGTGTTG. Tubulin served as an internal control with primer F: GACCTTGAATCGGCTTATGG and R: TATCCTGGGTGAACGCTTTG. The results were reported as an average of two biological repeats (two experiments each from 15 seedlings), each replicated three times per plate. mRNA abundance was calculated as fold change $=2^{\wedge}(\Delta \Delta \mathrm{Ct})=$ $2^{\wedge}[\Delta \mathrm{Ct}$ (treatment $)-\Delta \mathrm{Ct}($ control $\left.)\right]$, where $\Delta \Delta \mathrm{Ct}=\Delta \mathrm{Ct}(A C C$ oxidase treatment - tubulin treatment $)-\triangle \mathrm{Ct}(A C C$ oxidase control - tubulin control). $\Delta \mathrm{Ct}$ represents the difference in cycle numbers at which amplification first exceeds the threshold fluorescence level. We applied a one-way experimental design using two treatments.

EFFECT OF AVG, AN ETHYLENE SYNTHESIS ANTAGONIST, ON THE ROOT RESPONSE TO GLYCINE. We treated the seedlings in a manner similar to that described for the ACC oxidase gene expression analysis, although $1 \mu \mathrm{M} \mathrm{AVG}$ was added to the $\mathrm{KCl}$ and glycine (Gly) treatments. Control experiments were performed adding only $1 \mathrm{~mm} \mathrm{KCl}$ or $1 \mathrm{~mm}$ Gly to the medium without AVG. The PR length was measured after $3 \mathrm{~d}$ of treatments using a ruler. Fifteen seedlings were used for each treatment, and the experiments were performed twice. We applied a one-way experimental design using four treatments $(\mathrm{KCl}, \mathrm{KCl}+\mathrm{AVG}$, Gly, Gly + AVG) and one measurement time (PR growth at Day 3 of treatment).

Statistical analysis. The experimental design used was specified for each experiment. The results are representative of two (dose-response experiment and AVG experiments) or three (amino acids effect experiment and $\mathrm{pH}$ or light conditions experiments) independent experiments. The results of two independent experiments were shown together for starch analysis and $A C C$ oxidase expression. The results were compared using Tukey's adjusted test for multiple comparisons $(P<$ 0.05 ) after a one-way analysis of variance (Proc GLM, SAS Version 9.1; SAS Institute, Cary, NC) was conducted. Realtime PCR data were analyzed in Excel (Microsoft, Redmond, WA) and subjected to Student's $t$ test.

\section{Results and Discussion}

GLYCINE INHIBITS THE PRIMARY ROOT GROWTH OF THE habanero PepPer. Previous studies have shown that only L-glutamate had a significant effect on the root growth of $A$. thaliana (Walch-Liu et al., 2006b). To determine whether this amino acid could affect the PR growth of the habanero pepper, we initially tested the effect of $1 \mathrm{~mm} \mathrm{~L}$-glutamate on the PR of aseptically grown seedlings under conditions that were similar to those that were tested for $A$. thaliana (i.e., photoperiod conditions and $\mathrm{pH}$ 5.7) (Walch-Liu et al., 2006b). L-glutamate 
did not alter the root growth of the habanero pepper when compared with control with $\mathrm{KCl}$ (Fig. 1A), which contrasts with what was previously reported for $A$. thaliana (Kim et al., 2010; Walch-Liu and Forde, 2008; Walch-Liu et al., 2006b).

The dose-response curve demonstrated that a range between 0.25 and $5 \mathrm{~mm}$ of L-glutamate had no effect on root growth. The root growth (mean \pm SE, $\mathrm{n}=15$ seedlings) on Day 4 was $3.82 \pm 0.20,4.01 \pm 0.19,4.09 \pm$ $0.18,3.84 \pm 0.20,3.78 \pm 0.10$, and $3.76 \pm 0.13$ $\mathrm{cm}$ for $0,0.25,0.50,0.75,1$, and $5 \mathrm{~mm}$ of Lglutamate, respectively.

Root growth in the presence of $1 \mathrm{~mm}$ D-glutamate $(3.92 \pm 0.15 \mathrm{~cm})$ was similar to the control with $1 \mathrm{~mm} \mathrm{KCl}(3.75 \pm 0.21 \mathrm{~cm})$ after $4 \mathrm{~d}$ of treatment. The presence of $0.5 \mathrm{~mm}$ L-glutamine did not change the root response to L-glutamate $(3.91 \pm 0.22$ and $3.82 \pm 0.16 \mathrm{~cm}$ without or with L-glutamine, respectively), which demonstrates that there is no interaction between L-glutamine and L-glutamate on the PR growth of the habanero pepper.

We also examined the effect of other abundant amino acids in the soil such as L-aspartate and glycine. Using similar conditions to those that were described, L-aspartate did not affect root growth, which was $3.50 \pm$ $0.10 \mathrm{~cm}$ on Day 4 of treatment, but the same concentration of glycine significantly inhibited root growth by $20 \%$ (Fig. 1A).

$\mathrm{pH}$ and light conditions play an important role in the plant response to signals (Brenner et al., 2000; Hu et al., 2011; Thornton, 2001). The habanero pepper is typically grown in soil at pH 7.5 in the Yucatán (Borges-Gómez et al., 2008). In this study, we tested the effects of L-glutamate and glycine on seedling root growth at $\mathrm{pH} 7.5$ under normal photoperiod conditions and at $\mathrm{pH} 5.7$ and 7.5 on seedlings grown in the dark. The inhibitory effect of glycine was lost at $\mathrm{pH}$ 7.5 in normal photoperiod conditions (Fig. 1A). However, when the experiment was conducted under dark conditions, the inhibition of root growth by glycine was $\approx 30 \%$ after $4 \mathrm{~d}$ of treatment, independent of the $\mathrm{pH}$ conditions of the medium (Fig. 1B). The habanero pepper root was insensitive to L-glutamate under all test conditions (Fig. 1A-B).

When the effects of amino acid were evaluated over time, no significant differences in PR growth were observed between treatments on the first day of treatment (Fig. 2). However, glycine-treated roots that were exposed to normal photoperiod conditions at $\mathrm{pH} 5.7$ consistently exhibited a PR growth rate that was significantly lower $\left(0.75 \mathrm{~cm} \cdot \mathrm{d}^{-1}\right)$ at all time points when compared with roots that were grown in the presence of $\mathrm{KCl}$
Photoperiod

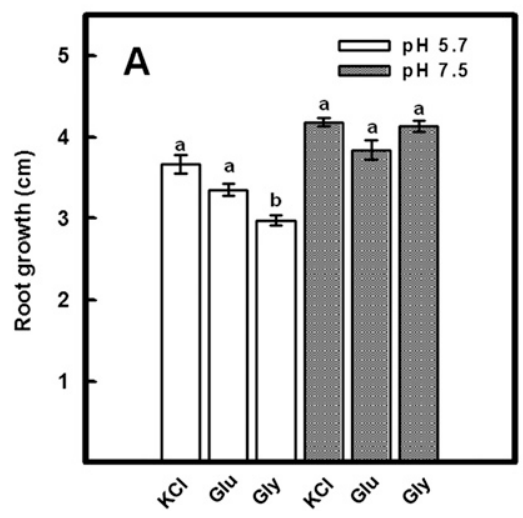

Dark

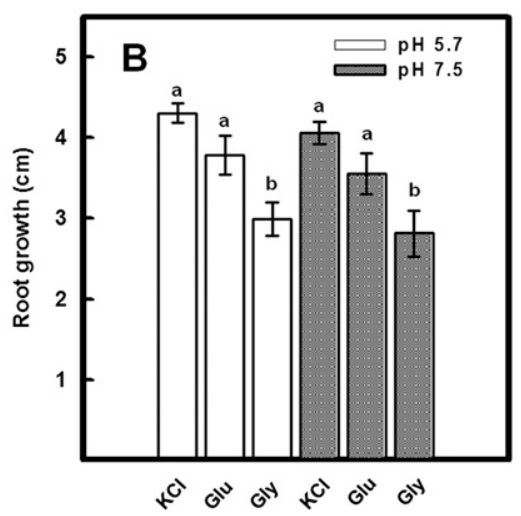

Fig. 1. Exogenous glycine inhibited habanero pepper primary root (PR) growth and the effect depended on the $\mathrm{pH}$ and light conditions. (A) PR length of the habanero pepper seedlings grown in media containing $1 \mathrm{~mm} \mathrm{KCl}$ (control), L-glutamate (Glu), or glycine (Gly) for $4 \mathrm{~d}$ in normal photoperiod conditions at $\mathrm{pH} 5.7$ and 7.5. (B) Seedlings were subjected to conditions similar to $\mathbf{A}$, except that seedlings were grown in the dark at $\mathrm{pH} 5.7$ and 7.5. Figures show the data of a representative experiment of three repetitions. Data are mean \pm SE of 15 seedlings and bars with different letters represent significant differences $(P \leq 0.005)$ within a $\mathrm{pH}$ treatment using Tukey's adjusted test for multiple comparisons.

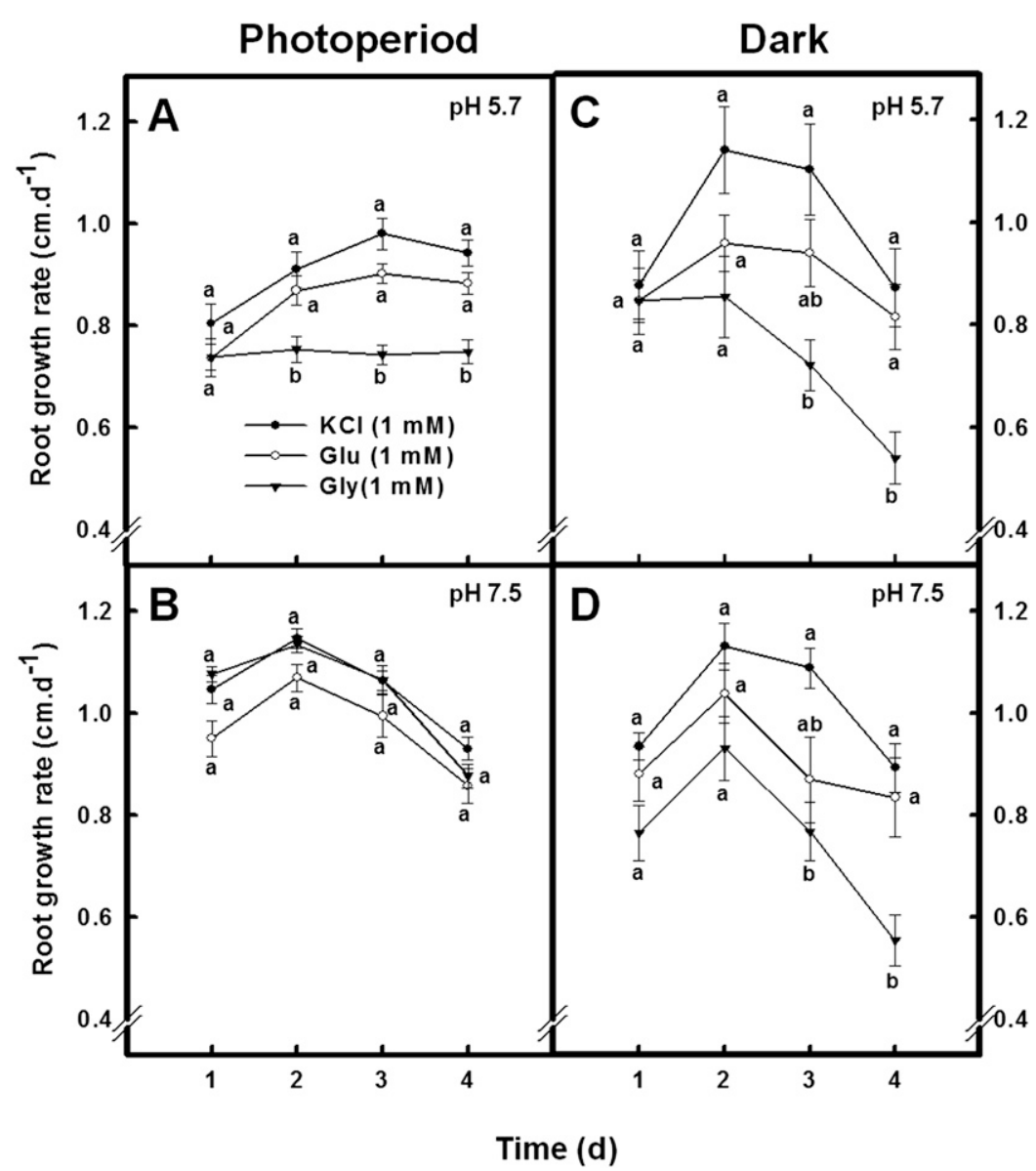

Fig. 2. Time course of changes in the primary root (PR) growth rate during exposure to L-glutamate or glycine. Seedlings grown in normal photoperiod conditions $(\mathbf{A}-\mathbf{B})$ or in the dark $(\mathbf{C}-\mathbf{D})$ were exposed to L-glutamate (Glu) or glycine (Gly) at pH 5.7 (A-C) or pH 7.5 (B-D). PR growth rates in each 24-h period after the experiment began were calculated from daily measurements of root length. Figures show the data of a representative experiment of three repetitions. Data are mean $\pm \mathrm{SE}$ of 15 seedlings. Different letters represent significant differences $(P \leq 0.005)$ between treatments by day using Tukey's adjusted test for multiple comparisons. 

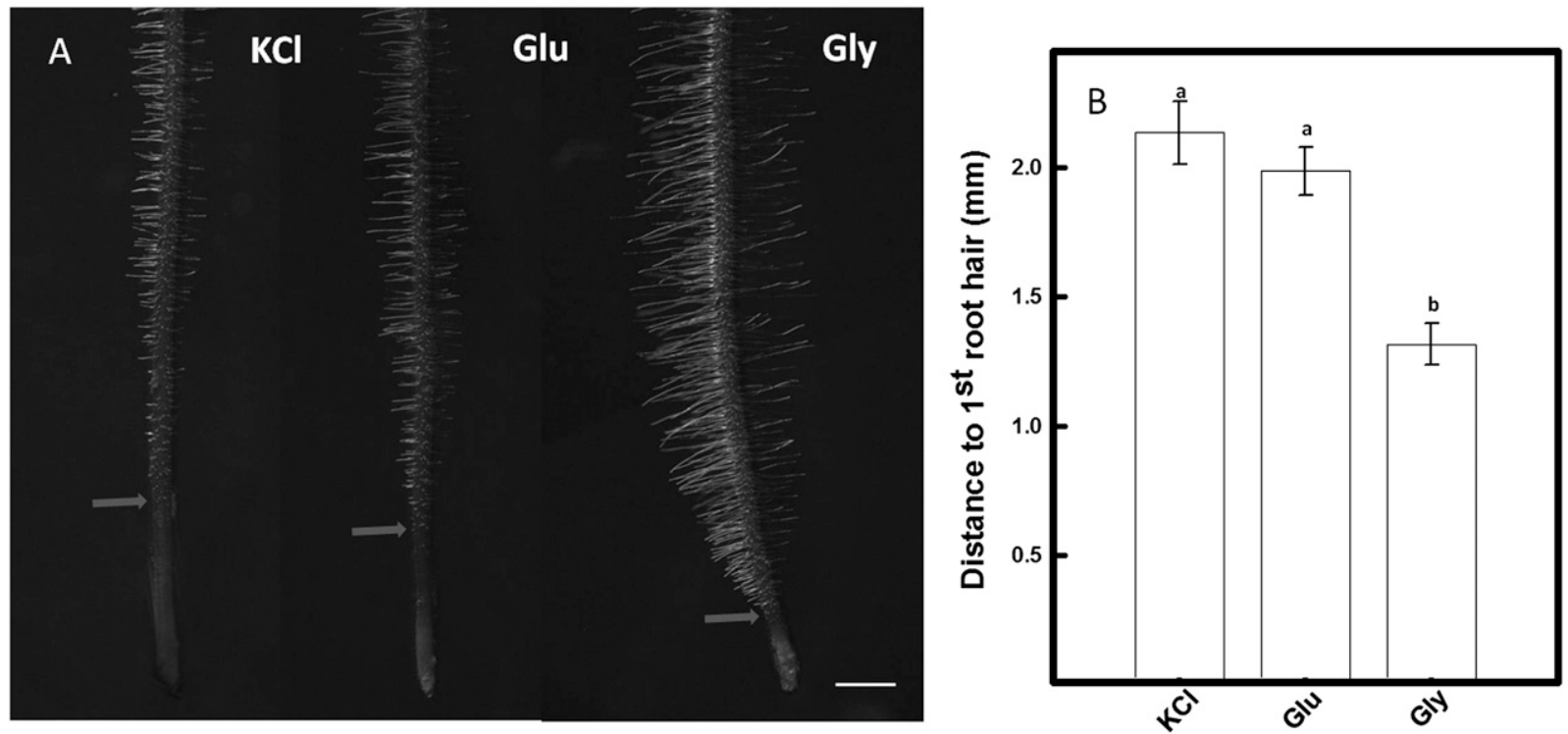

Fig. 3. Effect of L-glutamate and glycine on root tip morphology. Habanero pepper seedlings were transferred to plates containing $1 \mathrm{~mm} \mathrm{KCl}$ (control) or $1 \mathrm{~mm} \mathrm{~L}$ glutamate (Glu) or glycine (Gly) (treatments). (A) Primary root tips from seedlings grown in the dark at pH 5.7 for $4 \mathrm{~d}$ were photographed in situ on the surface of the agar plates. Arrow indicates of beginning of hair roots formation. Scale bar represents $1 \mathrm{~mm}$. (B) The distance from the root apex to the first root hair was calculated from both longitudinal sections. Values represent the mean \pm SD of three roots. Different letters represent significant differences using Tukey's adjusted test for multiple comparisons $(P=0.003)$.

Table 1. The effect of $1 \mathrm{~mm}$ glycine and $1 \mathrm{~mm}$ L-glutamate on the meristematic, transition, and elongation zone lengths, cell number, and mean cell length of different zones from the root apex of habanero pepper.

\begin{tabular}{|c|c|c|c|c|c|c|c|c|c|}
\hline \multirow[b]{3}{*}{ Treatment $^{\mathrm{z}}$} & \multicolumn{3}{|c|}{ Meristematic zone } & \multicolumn{3}{|c|}{ Transition zone } & \multicolumn{3}{|c|}{ Elongation zone } \\
\hline & $\begin{array}{l}\text { Length } \\
(\mu \mathrm{m})^{\mathrm{y}}\end{array}$ & $\begin{array}{l}\text { Cells } \\
\text { (no.) }\end{array}$ & $\begin{array}{c}\text { Mean cell } \\
\text { length }(\mu \mathrm{m})\end{array}$ & $\begin{array}{l}\text { Length } \\
(\mu \mathrm{m})^{\mathrm{y}}\end{array}$ & $\begin{array}{l}\text { Cells } \\
\text { (no.) }\end{array}$ & $\begin{array}{l}\text { Mean cell } \\
\text { length }(\mu \mathrm{m})\end{array}$ & $\begin{array}{l}\text { Length } \\
(\mu \mathrm{m})^{\mathrm{y}}\end{array}$ & $\begin{array}{l}\text { Cells } \\
\text { (no.) }\end{array}$ & $\begin{array}{c}\text { Mean cell } \\
\text { length }(\mu \mathrm{m})\end{array}$ \\
\hline & & & & & mean \pm & & & & \\
\hline Glu & $433 \pm 15$ & $40 \pm 1$ & $10 \pm 0.3$ & $278 \pm 21$ & $10 \pm 2$ & $26 \pm 2$ & $1189 \pm 51$ & $11 \pm 1$ & $101 \pm 9$ \\
\hline Gly & $263 \pm 25^{* *}$ & $30 \pm 6$ & $9 \pm 0.2^{*}$ & $234 \pm 13$ & $14 \pm 2$ & $17 \pm 1^{* *}$ & $573 \pm 32 * *$ & $9 \pm 2$ & $61 \pm 6^{* *}$ \\
\hline
\end{tabular}

${ }^{\mathrm{z}}$ Seedlings grown for $3 \mathrm{~d}$ in the dark at $\mathrm{pH} 5.7$ with $1 \mathrm{~mm} \mathrm{KCl}$ (control), $1 \mathrm{~mm}$ L-glutamate (Glu), and glycine (Gly).

y To quantify the root zone lengths, the start and the end of each zone was designed as describe in Figure 4 . The zone sizes were determined from longitudinal section viewed using a light microscope (Primo Star; Carl Zeiss, Göttingen, Germany).

${ }^{x}$ Values represent the mean of three roots. Statistical analysis was performed by comparing each treatment with the control (KCl) only using

Tukey's adjusted test for multiple comparisons.

*,**Significant at $P<0.001, P<0.0003$, respectively.

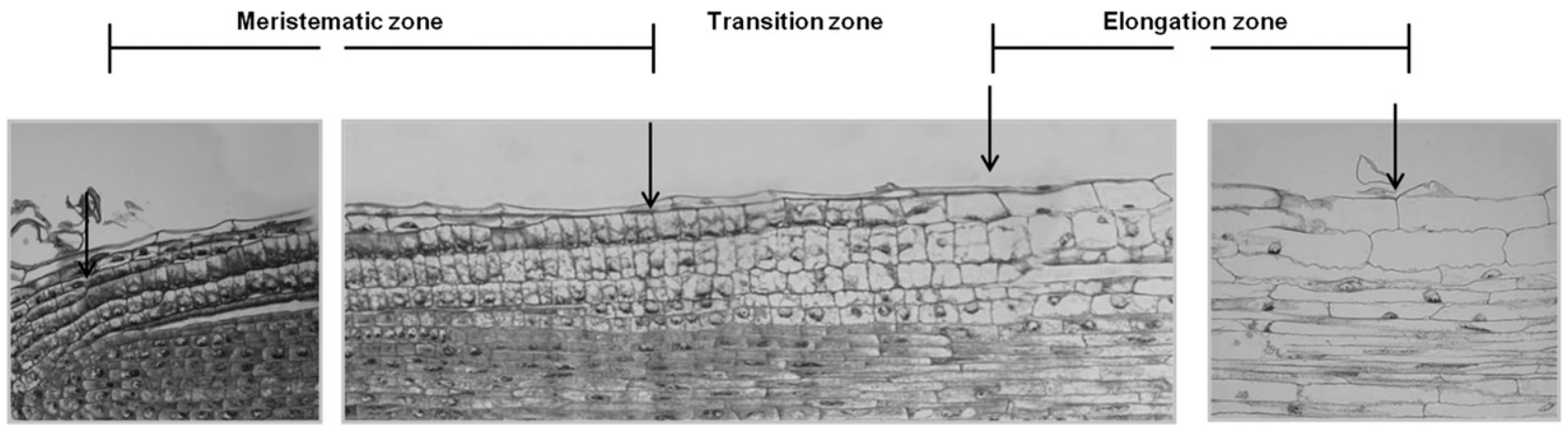

Fig. 4. Representation of the beginning and end of the meristematic, transition, and elongation zones that were examined in this study. The initial and end points of each zone are indicated by vertical arrows.

$\left(\approx 1 \mathrm{~cm} \cdot \mathrm{d}^{-1}\right.$ at $\left.3 \mathrm{~d}\right)$ (Fig. $\left.2 \mathrm{~A}\right)$. The PR growth rate for roots grown in $1 \mathrm{~mm} \mathrm{KCl}$ in the dark, at either of the two $\mathrm{pH}$ conditions, was $\approx 1.2 \mathrm{~cm} \cdot \mathrm{d}^{-1}$, whereas in roots that were treated with $1 \mathrm{~mm}$ glycine, a lower growth rate $\left(\approx 0.55 \mathrm{~cm} \cdot \mathrm{d}^{-1}\right)$ was observed after $4 \mathrm{~d}$ (Fig. 2C-D). No effect was observed when the roots were exposed to any of the amino acids in normal photoperiod conditions at $\mathrm{pH} 7.5$ (Fig. 2B). Based on the results presented, L-glutamate-treated roots did not significantly grow 
slower than roots that were treated with $\mathrm{KCl}$ in the dark (Fig. 2C-D).

The effects of glycine shown here are novel and do not seem to be caused by an alteration in the $\mathrm{N}$ content applied to the root, because applying the same concentration of other amino acids such as L-glutamate, L-aspartate, and L-glutamine did not significantly modify root growth. Our results regarding glycine and root growth contrast with those that were reported previously for L-glutamate. Walch-Liu et al. (2006b) reported that $A$. thaliana roots from ecotype $\mathrm{C} 24$ were more susceptible to lose the ability to resume root growth after $3 \mathrm{~d}$ of treatment with micromolar concentrations of L-glutamate, which suggested a loss of the meristem. The inhibitory effect of glycine on the habanero pepper PR was dependent on the $\mathrm{pH}$ of the medium, especially when the plants were grown under normal photoperiod conditions but not when they were grown in the dark. This result suggests that glycine induces specific events in different light conditions, and these events are differentiated by their $\mathrm{pH}$ sensitivities.

Reportedly, the inhibitory effect of L-glutamate on the $A$. thaliana root could result from low $\mathrm{pH}$ toxicity because this effect was also caused by other acidic amino acids such as L-aspartate (Kim et al., 2010). We eliminated this possibility because glycine is a neutral amino acid and acidic amino acids did not affect habanero pepper growth.

However, the $\mathrm{pH}$ of the medium may interfere with glycine uptake. The uptake of many amino acids by plants is $\mathrm{pH}$ dependent, ranging between $\mathrm{pH} 4$ and $\mathrm{pH} 6$ (van Bel et al., 1981). Glycine uptake in Hordeum vulgare occurs at an optimal $\mathrm{pH}$ of 5.8 (Lien and Rognes, 1997); a pH increase from 3.5 to 9.2 causes a reduction in glycine uptake in Lolium perenne (Thornton, 2001), and glycine uptake by Pisum sativum shows little change between $\mathrm{pH} 2$ to 9 (Dureja et al., 1984).

GLYCINE INHIBITED CELL ELONGATION BUT NOT CELL NUMBER IN ROOT TIPS. Because glycine had a greater effect on the root growth of seedlings grown in dark conditions at $\mathrm{pH}$ 5.7, we selected this treatment to further analyze the response of the habanero pepper root to amino acids. Figure 3A shows images of the root tips of amino acid-treated seedlings after $4 \mathrm{~d}$, in which drastic effects were observed in glycine-treated roots. The glycine treatment produced longer root hairs than the KCl-treated and L-glutamate-treated seedlings (Fig. 3A), and the distance from the root apex to the first root hair was markedly reduced in this treatment (35\%; Fig. 3B), which indicated a decrease in the size of the meristem and/or elongation zone. The habanero pepper seedlings did not produce visible lateral roots after $4 \mathrm{~d}$ in any of the tested treatments.

To determine the zone affected on the root apex by glycine, we measured the lengths of the meristematic, transition (low elongation rate), and elongation zones (fast elongation) from longitudinal sections of roots treated for
$3 \mathrm{~d}$ with $1 \mathrm{~mm}$ glycine, $1 \mathrm{~mm}$ L-glutamate, or $1 \mathrm{~mm} \mathrm{KCl}$ (control) in seedlings grown in the dark at $\mathrm{pH}$ 5.7. As illustrated in Table 1, when treated with $1 \mathrm{~mm}$ glycine, the meristematic and elongation zones of seedlings decreased in length by $\approx 36 \%$ and $53 \%$, respectively, but the transition zone length was not significantly

Table 2. The effect of $1 \mathrm{~mm}$ glycine and $1 \mathrm{~mm}$ L-glutamate on the radical diameter of habanero pepper roots.

\begin{tabular}{llccc}
\hline \multicolumn{5}{c}{ Distance from root apex $(\mu \mathrm{m})$} \\
\hline Treatment $^{\mathrm{z}}$ & 330 & 500 & 996 & 2331 \\
& \multicolumn{4}{c}{ Radical diam $[\text { mean } \pm \text { SD }(\mu \mathrm{m})]^{\mathrm{y}}$} \\
$\mathrm{KCl}$ & $188 \pm 1^{\mathrm{x}}$ & $197 \pm 1$ & $208 \pm 1$ & $198 \pm 2$ \\
$\mathrm{Glu}$ & $191 \pm 2$ & $201 \pm 2$ & $202 \pm 3$ & $194 \pm 4$ \\
Gly & $202 \pm 2^{*}$ & $252 \pm 18^{*}$ & $235 \pm 10^{*}$ & $216 \pm 6^{*}$
\end{tabular}

${ }^{z}$ Seedlings were subjected to $1 \mathrm{~mm} \mathrm{KCl} \mathrm{(control),} 1 \mathrm{~mm}$ L-glutamate (Glu), or $1 \mathrm{~mm}$ glycine for $3 \mathrm{~d}$ in the dark at $\mathrm{pH}$ 5.7.

${ }^{\mathrm{y}}$ The radical diameter of roots was calculated from transverse sections $(3 \mu \mathrm{m})$ from root tips (three roots per treatment) at different distances from root apex: 330, 500, 996, and $2331 \mu \mathrm{m}$.

${ }^{x}$ Data are a mean value of three roots. Statistical analysis was performed by comparing each treatment to the control $(\mathrm{KCl})$ only using Tukey's adjusted test for multiple comparisons.

*Significant at $P \leq 0.005$.
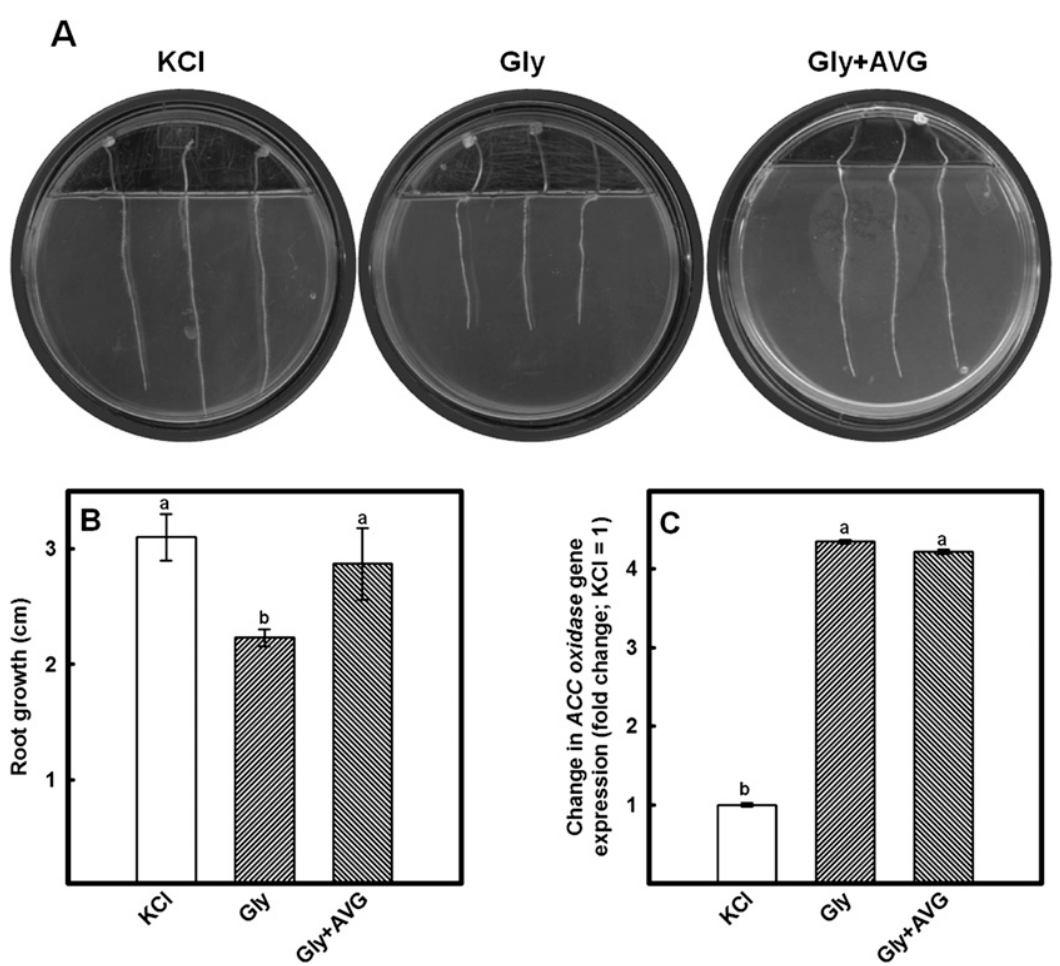

Fig. 5. Role of ethylene on root responses to glycine. (A) Aminoethoxyvinylglycine (AVG) reversed the inhibitory effect of glycine on primary root (PR) growth. Representative images of roots treated for $3 \mathrm{~d}$ with $1 \mathrm{~mm} \mathrm{KCl}$ (control), $1 \mathrm{~mm}$ glycine (Gly), or $1 \mathrm{~mm} \mathrm{Gly}+1 \mu \mathrm{M} \mathrm{AVG}$ (B). The PR lengths of the seedlings grown on a medium containing $1 \mathrm{~mm} \mathrm{KCl}, 1 \mathrm{~mm}$ Gly, or $1 \mathrm{~mm}$ Gly $+1 \mu \mathrm{M}$ AVG for $3 \mathrm{~d}$ under dark conditions at $\mathrm{pH}$ 5.7. Figure shows data of a representative experiment of two repetitions and data are mean \pm SE of 15 seedlings. Different letters represent significant differences $(P<0.05)$. (C) Effect of glycine on the expression level of 1-aminocyclopropane-1-carboxylic acid $(A C C)$ oxidase in the root apex. RNA was extracted from $8 \mathrm{~mm}$ of the root apex of seedlings exposed to $1 \mathrm{~mm} \mathrm{KCl}, 1 \mathrm{~mm}$ Gly, or $1 \mathrm{~mm}$ Gly $+1 \mu \mathrm{M}$ AVG and grown for $3 \mathrm{~d}$ in the dark at $\mathrm{pH}$ 5.7. mRNA abundance was calculated as fold change $=2^{\wedge}[\Delta \mathrm{Ct}$ (treatment) $-\Delta \mathrm{Ct}$ (control) $]$. One fold indicates ACC oxidase gene expression in control roots treated with $1 \mathrm{~mm} \mathrm{KCl}$. Tubulin was used as reference gene and showed less than $10 \%$ variability. Values are mean \pm SD of two experiments. Different letters represent significant difference using Student's $t$ test $(P<0.05)$. 
affected when compared with a control that was not treated with glycine (Table 1). L-glutamate did not affect the lengths of root zones (Table 1).

Because cell division and cell elongation contribute to root length, we quantified the total cell number and mean cell length in a single file of epidermal cells by using a longitudinal section through the root apex. The beginning and end of the meristematic zone was considered to be the epidermal cell above the T-division and the first visible change in epidermal cell size, respectively (Fig. 4). We considered the transition zone to begin at the end of the meristematic zone and to continue into the drastically increased longitudinal cell expansion of the epidermis cell (Fig. 4). Additionally, we designated this region as the starting point of the elongation zone. The end of the elongation zone was marked as the epidermal cell that formed the first hair root (Fig. 4).

The addition of $1 \mathrm{~mm}$ glycine to the growth medium of habanero pepper roots did not significantly change the longitudinal cell number in the root apex zones, although these values were slightly lower in the meristematic and elongation zones when compared with those that were observed in KCl-treated roots, as illustrated in Table 1. However, the mean cell length was lower in all of the apex zones of glycine-treated roots and the maximum glycine inhibitory effect on cell expansion was observed in the fast elongation zone, which was 51\% lower (Table 1). This observation was consistent with the inhibition that was found in the elongation zone. L-glutamate had no effect on these parameters (Table 1).

Under our conditions, the root cells of $\mathrm{KCl}$-, L-glutamate-, and glycine-treated roots entered the transition zone stage with an average cell length of 10,10 , or $9 \mu \mathrm{m}$, respectively, and increased their length to $126 \mu \mathrm{m}$ (a 13-fold increase), $101 \mu \mathrm{m}$ (a 10-fold increase), or $61.4 \mu \mathrm{m}$ (a 7-fold increase), respectively, when they arrived at the differentiation zone stage (Table 1). Subsequently, glycine inhibition on cellular elongation was $\approx 35 \%$, which was similar to the inhibition of root growth by this amino acid. We conclude that glycine inhibits habanero pepper PR growth by reducing cell elongation. Additionally, a significant increase in root width was observed in seedlings that were grown in the presence of glycine for $3 \mathrm{~d}$ (Table 2). L-glutamate did not affect the root width (Table 2).

The glycine-induced phenotype in our work is consistent with the results observed in ethylene studies: cell elongation inhibition, stimulation in radial expansion, and root hair elongation ( $\mathrm{Hu}$ et al., 2011; Leblanc et al., 2008; Strader et al., 2010). It is known that ethylene controls root cell expansion

A

E through auxin (Strader et al., 2010) by inhibiting plasma membrane $\mathrm{H}^{+}$-ATPase activity (Staal et al., 2011). It has been reported that amino acids, particularly L-glutamate, could act upstream of ethylene to induce changes in root elongation and act as an endogenous signal (Leblanc et al., 2008).

AVG REVERSED THE INHIBITORY EFFECT OF GLYCINE. TO determine whether the inhibitory effect of glycine on PR growth is a result of ethylene production, we then investigated

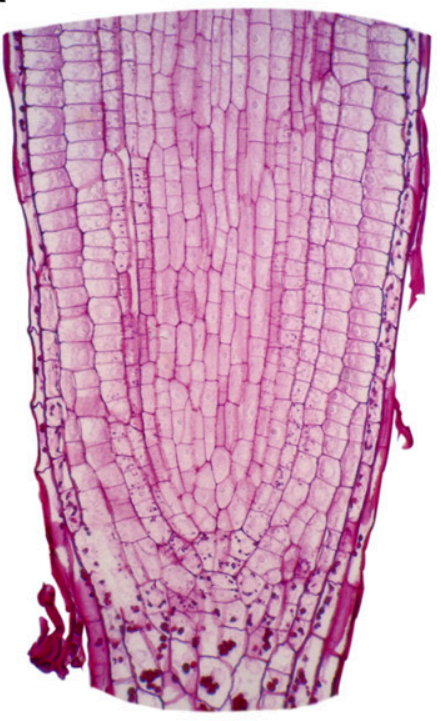

C
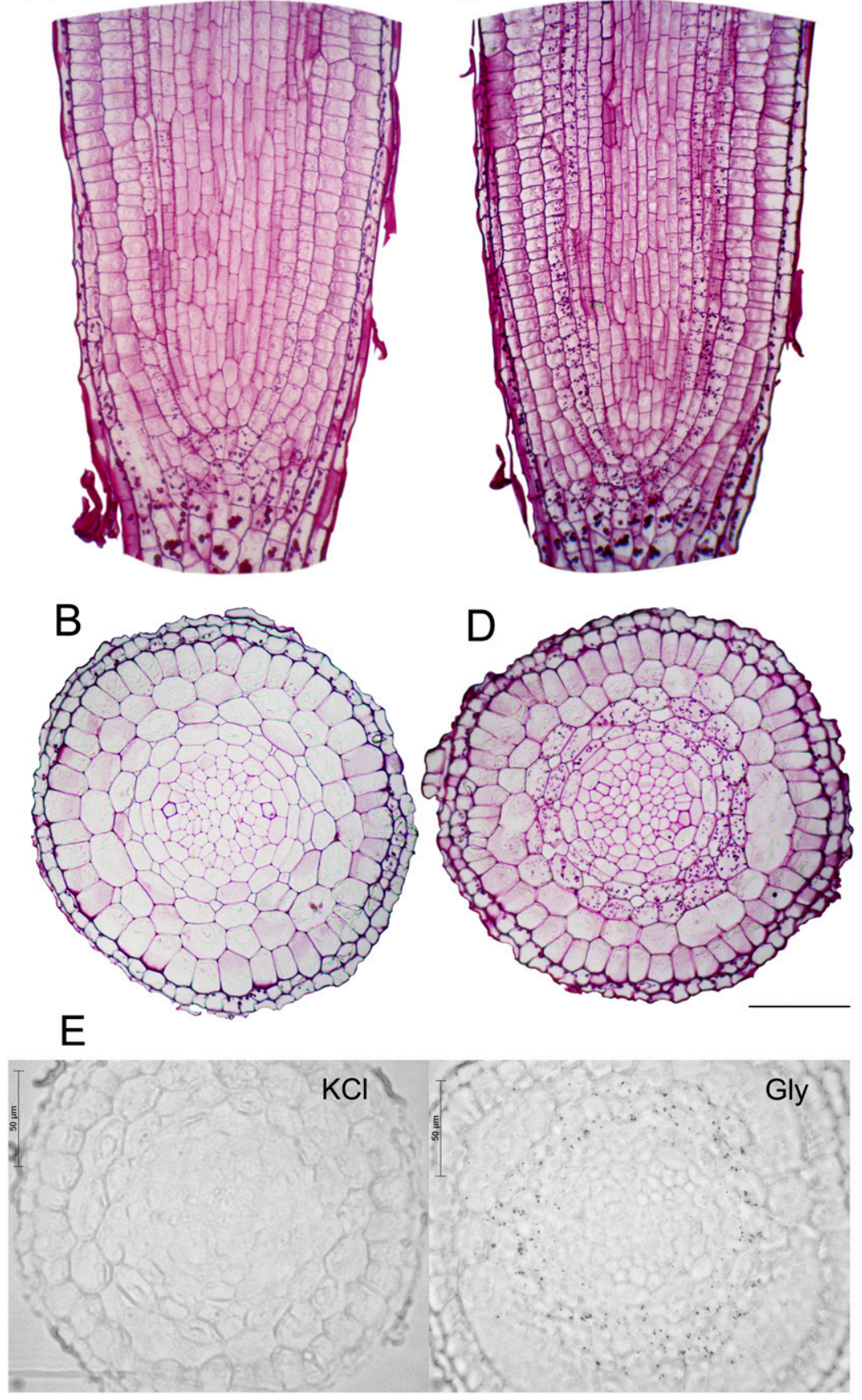

Fig. 6. Cellular localization of starch grains in the habanero pepper primary root tip. Longitudinal and transverse sections show prominent starch grain accumulation in root tips treated with glycine $(\mathbf{C}-\mathbf{D})$ compared with those treated with $\mathrm{KCl}(\mathbf{A}-\mathbf{B})$. Root tips were collected from seedlings grown in the dark at $\mathrm{pH} 5.7$ after $3 \mathrm{~d}$ of treatment. Images in $\mathbf{B}$ and $\mathbf{D}$ are transverse sections $(3 \mu \mathrm{m}) 500 \mu \mathrm{m}$ from the root tip. Scale bar $=50 \mu \mathrm{m}$. Transverse sections stained with Schiff reagent. (E) Transverse sections stained with Lugol's iodine staining. 
the effect of AVG, which is an antagonist of aminocyclopropane carboxylic acid synthase (Satoh and Yang, 1989), on PR growth in the presence of glycine and $\mathrm{KCl}$ (control) for $3 \mathrm{~d}$. The presence of $1 \mu \mathrm{M}$ AVG did not affect root growth in the control with $\mathrm{KCl}(3.1 \pm 0.2$ and $3.3 \pm 0.3 \mathrm{~cm}$ without or with $\mathrm{AVG}$, respectively). AVG effectively reversed the glycine-mediated reduction in habanero pepper PR growth (Fig. 5A-B), indicating that ethylene may be responsible for the inhibition of PR growth in the presence of glycine.

GLYCINE INCREASED THE TRANSCRIPT LEVELS OF ACC OXIDASE. ACC oxidase plays a role in regulating plant ethylene levels (Kende, 1993; Tian et al., 2009). We evaluated the expression levels of ACC oxidase from the root apex $(8 \mathrm{~mm})$ of habanero pepper seedlings grown for $3 \mathrm{~d}$ in the dark at $\mathrm{pH} 5.7$ in the presence of $\mathrm{KCl}$, glycine, or glycine $+\mathrm{AVG}$. As illustrated in Figure 5C, glycine treatment increased the expression of $A C C$ oxidase 4-fold in the root apex compared with $\mathrm{KCl}$-treated roots. However, AVG does not have an effect at the transcript level of ACC oxidase (Fig. 5C) as was previously reported for Nicotiana tabacum (Avni et al., 1994).

Together, the results of our pharmacological and molecular approaches suggest that the inhibitory effect of glycine on habanero pepper PR growth is likely the result of elevated ethylene production.

GLYCINE AFFECTS STARCH ACCUMULATION IN HABANERo PEPPER ROOT TIPS. We detected substantial differences in the appearance and distribution of starch grains between the $\mathrm{KCl}$ and glycine-treated roots. In the $\mathrm{KCl}$-treated roots, the starch grains were never detected in the transition and elongation zones, whereas a few starch grains were observed in the more apical region of the meristematic zone (Fig. 6A-B). However, in the glycine-treated roots, the starch grains were highly abundant in all of the meristematic zones and although less abundant, these grains were still visible in the transition zone but disappeared at the end of the elongation zone (Fig. 6C-D).

Interestingly, the accumulation of starch grains by glycine treatment occurred specifically in the internal cortical layers with a minor portion in the endodermal layer as illustrated in Figure 6D. Although very rare, some starch grains were also noted in the outer cortical layer and pericycle of glycinetreated roots. Starch grains were absent in the epidermal cells and vascular tissue in roots from both treatments (Fig. 6C-D). These data also were confirmed by Lugol's iodine staining (Fig. 6E).

The starch content was higher in the root tip of seedlings growing in the presence of glycine $\left[2.91 \pm 0.96 \mathrm{mg} \cdot \mathrm{g}^{-1}\right.$ fresh weight $(\mathrm{FW})]$ compared with the seedlings treated with $\mathrm{KCl}$ $\left(0.73 \pm 0.10 \mathrm{mg} \cdot \mathrm{g}^{-1} \mathrm{FW}\right)(\mathrm{n}=6$, two samples replicated three times, $P=0.05)$. Together with the anatomical analysis, these results confirm that glycine induced an accumulation of starch in habanero pepper root tips.

Carbon (C) and $\mathrm{N}$ metabolism inherently depend on each other because $\mathrm{C}$ skeletons are required for $\mathrm{N}$ assimilation. Interestingly, ethylene can induce accumulation of starch granules through the ETR2 receptor. This receptor inhibits the expression of $\alpha$-amylase, which is an enzyme that is involved in the degradation of starch, and a monosaccharide transporter, which leads to inhibition of sugar translocation (Wuriyanghan et al., 2009). However, the iGLR-type receptors (ionotropic glutamate receptor) also can be important in $\mathrm{C} / \mathrm{N}$ integration and the activation of these receptors by glycine may lead to starch biosynthesis (Dubos et al., 2005).
Soil acid hydrolysis produces between $20 \%$ and $50 \%$ of the total $\mathrm{N}$ as amino acids (Lipson and Näsholm, 2001). Glycine is one of the most abundant amino acids in soil, and the largest source of this amino acid for plants is most likely through the hydrolysis of protein and peptides by extracellular enzymes (Lipson and Näsholm, 2001). Glycine is more available to plants because it is a poor $\mathrm{C}$ source for microbes compared with other amino acids (Lipson et al., 1999). Additionally, it has been reported that the endogenous glycine concentration may exhibit large diurnal fluctuations in response to altered carbon dioxide levels, which is in contrast to L-glutamate, whose endogenous levels changed very little (Geiger et al., 1998). This observation suggests that glycine could function as a signaling molecule.

Our work describes a role for glycine in the habanero pepper root apex that has not been previously reported. The suppression of root growth by decreasing cellular elongation, stimulating root hair elongation, and increasing the starch content in root tips could be a glycine-induced adaptive response of some plants when they are growing in soils with high contents of organic matter. Recently, it has been reported that a similar root phenotype, which was induced by ethylene through auxin, is required for Solanum lycopersicum root penetration into the soil (Santisree et al., 2011).

The presence of exogenous glycine may arrest habanero pepper root growth to allow the roots to remain longer in nutrient-enriched niches found near decaying organic matter. Glycine promotes root hair growth that allows access to a greater surface area and volume of soil, which can favor both the acquisition of water and nutrients in these niches. In particular, roots hairs may be very important for the acquisition of soil resources that move only small distances by diffusion such as phosphorus, K, and micronutrient metals (Marschner, 1995). Given that the response to glycine could be advantageous to increase growth and nutrient acquisition for habanero pepper, field trials should include applying this amino acid to plants either directly or included in a fertilizer's formulation. Our results suggest that ethylene regulates root hair elongation and the arrest of habanero pepper root growth in response to the presence of glycine in the soil.

\section{Literature Cited}

Alvarez, J.M., E.A. Vidal, and R.A. Gutiérrez. 2012. Integration of local and systemic pathways for plant $\mathrm{N}$ response. Curr. Opin. Plant Biol. 15:185-191.

Avni, A., B.A. Bailey, A.K. Mattoo, and J.D. Anderson. 1994. Induction of ethylene biosynthesis in Nicotiana tabacum by a Trichoderma viride xylanase is correlated to the accumulation of 1-aminocyclopropane-1-carboxylic acid (ACC) synthase and $A C C$ oxidase transcripts. Plant Physiol. 106:1049-1055.

Bautista, F., J. Navarro-Alberto, A. Manu, and R. Lozano. 2005. Microrelieve y color del suelo como propiedades de diagnóstico en zonas de karst reciente, p. 123-131. In: Bautista, F. and G. Palacios (eds.). Caracterización y manejo de los suelos de la península de Yucatan: Implicaciones agropecuarias, forestales y ambientales. Universidad Autonoma de Campeche, Campeche, Mexico.

Borges-Gómez, L., M. Soria-Fregoso, V. Casanova-Villarreal, E. Villanueva-Cohuo, and G. Pereyda-Perez. 2008. Correlation and calibration of phosphorus analysis in soil from Yucatan, México, for growing habanero peppers. Agrociencia 42:21-27.

Bosland, P.W. and E.J. Votava. 2000. Peppers: Vegetable and spice Capsicum. CABI, New York, NY.

Brenner, E.D., N. Martínez-Barboza, A.P. Clark, Q.S. Liang, D. Stevenson, and G.M. Coruzzi. 2000. Arabidopsis mutants resistant 
to $\mathrm{S}(+)-\beta$-methyl- $\alpha, \beta$ - diaminopropionic acid, a cycad derived glutamate receptor agonist. Plant Physiol. 124:1615-1624.

Celis-Arámburo, T.J., M. Carrillo-Pech, L.A. Castro-Concha, M.L. Miranda-Ham, M. Martinez-Estévez, and I. Echevarría-Machado. 2011. Exogenous nitrate induces root branching and inhibits primary root growth in Capsicum chinense Jacq. Plant Physiol. Biochem. 49:1456-1464.

Dakora, F.D. and D.A. Phillips. 2002. Root exudates as mediators of mineral acquisition in low-nutrient environments. Plant Soil 245:35-47.

Dubos, C., J. Willment, D. Huggins, G.H. Grant, and M.M. Campbell. 2005. Kanamicin reveals the role played by glutamate receptors in shaping plant resource allocation. Plant J. 43:348-355.

Dubrovsky, J.G., G.A. Gambetta, A. Hernández-Barrera, S. Shishkova, and I. González. 2006. Lateral root initiation in Arabidopsis: Developmental window, spatial patterning, density and predictability. Ann. Bot. (Lond.) 97:903-915.

Dureja, I., S. Guha-Mukherjee, and R. Prasad. 1984. Characteristics of transport of L-leucine and glycine in pea protoplasts. J. Expt. Bot. 35:1022-1031.

Forsum, O., H. Svennerstam, U. Ganeteg, and T. Náholm. 2008. Capacities and constraints of amino acid utilization in Arabidopsis. New Phytol. 179:1058-1069.

Gamborg, O.L., R.A. Miller, and K. Ojima. 1968. Nutrient requirements of suspension cultures of soybean root cells. Exp. Cell Res. 50:151-158.

Geiger, M., P. Walch-Liu, C. Engels, J. Parnecker, E.D. Schulze, F. Ludewig, U. Sonnewald, W.R. Scheible, and M. Stitt. 1998. Enhanced carbon dioxide leads to a modified diurnal rhythm of nitrate reductase activity in older plants, and large stimulation of nitrate reductase activity and higher levels of amino acids in young tobacco plants. Plant Cell Environ. 21:253-268.

Harris, G.P. 1956. Amino acids as source of nitrogen for the growth of isolated oat embryos. New Phytol. 55:253-268.

Harris, G.P. 1959. Amino acids as nitrogen sources for the growth of excised roots of red clover. New Phytol. 58:330-344.

Hodge, A. 2004. The plastic plant: Root responses to heterogeneous supplies of nutrient. New Phytol. 162:9-24.

Hu, Y., C. Chang, G. Xu, and T. Wang. 2011. Light restored root growth of Arabidopsis with constitutive ethylene response. Acta Physiol. Plant. 33:667-674.

Jones, D.L., J.R. Healey, V.B. Willett, J.F. Farrar, and A. Hodge. 2005. Dissolved organic nitrogen uptake by plants an important $\mathrm{N}$ uptake pathway? Soil Biol. Biochem. 37:413-423.

Kende, H. 1993. Ethylene biosynthesis. Annu. Rev. Plant Physiol. Plant Mol. Biol. 44:283-307.

Kim, T.H., E.C. Kim, S.W. Kim, H.S. Lee, and D.W. Choi. 2010. Exogenous glutamate inhibits the root growth and increases the glutamine content in Arabidopsis thaliana. J. Plant Biol. 53:45-51.

Leblanc, A., H. Renault, J. Lecourt, P. Etienne, C. Deleu, and E. Le Deunff. 2008. Elongation changes of exploratory and root hair systems induced by aminocyclopropane carboxylic acid and aminoethoxyvinylglycine affect nitrate uptake and BnNrt2.1 and BnNrt1.1 transporter gene expression in oilseed rape. Plant Physiol. 146:1928-1940.

Lien, R. and S.E. Rognes. 1997. Uptake of amino acids by barley leaf slices: Kinetics, specificity, and energetic. Physiol. Plant. 41:175183.

Lipson, D. and T. Näsholm. 2001. The unexpected versatility of plants: Organic nitrogen use and availability in terrestrial ecosystems. Oecologia 128:305-316.

Lipson, D.A., T.K. Raab, S.K. Schmidt, and R.K. Monson. 1999. Variation in competitive abilities of plants and microbes for specific amino acids. Biol. Fertil. Soils 29:257-261.

Lynch, J. and K.M. Brown. 1997. Ethylene and plant responses to nutritional stress. Physiol. Plant. 100:613-619.

Marschner, H. 1995. Mineral nutrition of higher plants. 2nd Ed. Academic Press, Harcourt Brace, New York, NY.
Masclaux-Daubresse, C., F. Daniel-Vedele, J. Dechorgnat, F. Chardon, L. Gaufichon, and A. Suzuki. 2010. Nitrogen uptake, assimilation and remobilization in plants: Challenges for sustainable and productive agriculture. Ann. Bot. (Lond.) 105:1141-1157.

McManus, J.F.A. 1961. Periodate oxidation techniques, p. 171-201. In: Danielli, J.F. (ed.). General cytochemical methods. Vol. 2. Academic Press, New York, NY.

Medina-Lara, F., I. Echevarría-Machado, R. Pacheco-Arjona, N. Ruiz-Lau, A. Guzmán-Antonio, and M. Martínez-Estévez. 2008. Influence of nitrogen and potassium fertilization on fruiting and capsaicin content in habanero pepper (Capsicum chinense Jacq.). HortScience 43:1549-1554.

Morgan, P.W. and M.C. Drew. 1997. Ethylene and plant responses to stress. Physiol. Plant. 100:620-630.

Núñez-Pastrana, R., G.F. Arcos-Ortega, R.A. Souza-Perera, C.A. Sánchez-Borges, Y.E. Nakazawa-Ueji, F.J. García-Villalobo, A.A. Guzmán-Antonio, and J.J. Zúñiga-Aguilar. 2011. Ethylene, but not salicylic acid or methyl jasmonate, induces a resistance response against Phytophthora capsici in habanero pepper. Eur. J. Plant Pathol. 131:669-683.

Ochoa-Alejo, A. and R. Ramirez-Malagon. 2001. In vitro chili pepper biotechnology. In Vitro Cell. Dev. Biol. Plant 37:701-729.

Öhlund, J. and T. Näsholm. 2004. Regulation and inorganic nitrogen uptake in scots pine (Pinus sylvestris) seedlings. Tree Physiol. 24:13971402.

Ponce, G., P.W. Barlow, L.J. Feldman, and G.I. Cassab. 2005. Auxin and ethylene interactions control mitotic activity of the quiescent centre, root cap size, and pattern of cap cell differentiation in maize. Plant Cell Environ. 28:719-732.

Ravishankar, G.A., B. Suresh, P. Giridhar, S.R. Rao, and T.S. Johnson. 2003. Biotechnological studies on Capsicum metabolite production and plant improvement, p. 96-128. In: Deca, A.K. (ed.). Capsicum: The genus Capsicum. Taylor, London, UK.

Rodas-García, R. and M. Collazo-Ortega. 2006. Determinación de productos de la fotosíntesis: Azúcares y almidón, p. 91-98. In: Rodas-García, R. and M. Collazo-Ortega (eds.). Manual de prácticas de fotosíntesis. Universidad Nacional Autónoma de Mexico, Mexico City, Mexico.

Santisree, P., S. Nongmaithem, H. Vasuki, Y. Sreelakshmi, M.G. Ivanchenko, and R. Sharma. 2011. Tomato root penetration in soil requires coactions between ethylene and auxin signaling. Plant Physiol. 156:1424-1438.

Satoh, S. and S.F. Yang. 1989. Inactivation of 1-aminocyclopropane1-carboxylate synthase by L-vinylglycine as related to the mechanismbased inactivation of the enzyme by S-adenosyl-L. methionine. Plant Physiol. 91:1036-1039.

Schneider, C.A., W.S. Rasband, and K.W. Eliceiri. 2012. NIH image to imageJ: 25 years of image analysis. Nat. Methods 9:671-675.

Skinner, J. and H. Street. 1954. Studies on the growth of excised roots II. Observations on the growth of excised groundsel roots. New Phytol. 53:44-67.

Staal, M., T.D. Cnodder, D. Simón, F. Vandenbussche, D.V. Der Straeten, J.P. Verbelen, T. Elzenga, and K. Vissenberg. 2011. Apoplastic alkalinization is Instrumental for the inhibition of cell elongation in the Arabidopsis root by the ethylene precursor 1-aminocyclopropane-carboxylic acid. Plant Physiol. 155:20492055.

Strader, L.C., G.L. Chen, and B. Bartel. 2010. Ethylene directs auxin to control root cell expansion. Plant J. 24:874-884.

Street, H.E., J.C. Hughes, and J.S. Lewis. 1960. Studies on the growth of excised roots. X. Individual amino acids and acid-hydrolysed casein as nitrogen sources for the growth of excised tomato roots. New Phytol. 59:273-287.

Thornton, B. 2001. Uptake of glycine by non-mycorrhizal Lolium perenne. J. Expt. Bot. 52:1315-1322.

Tian, Q.Y., P. Sun, and W.H. Zhang. 2009. Ethylene is involved in nitrate-dependent root growth and branching in Arabidopsis thaliana. New Phytol. 184:918-931. 
van Bel, A.J.E., P. van Leeuwenkamp, and C. van der Schoot. 1981. Amino acid uptake by various tissues of the tomato plant. Effects of the external $\mathrm{pH}$ and light. Zeitschrift fur Pflanzenphysiologie 104:117-128.

Walch-Liu, P. and B.G. Forde. 2008. Nitrate signaling mediated by the NRT1.1 nitrate transporter antagonizes L-glutamateinduced changes in root architecture. Plant J. 54:820828.

Walch-Liu, P., I.I. Ivanov, S. Filleur, Y. Gan, T. Remans, and B.G. Forde. 2006a. Nitrogen regulation of root branching. Ann. Bot. (Lond.) 97: $875-881$.
Walch-Liu, P., L. Lai-Hua, T. Remans, M. Tester, and B.G. Forde. 2006b. Evidence that L-glutamate can act as an exogenous signal to modulate roots growth and branching in Arabidopsis thaliana. Plant Cell Physiol. 47:1045-1057.

Wang, D. and P.W. Bosland. 2006. The genes of Capsicum. HortScience 41:1169-1187.

Wuriyanghan, H., B. Zhang, W.H. Cao, B. Ma, G. Lei, Y.F. Liu, W. Wei, H.J. Wu, L.J. Chen, H.W. Chen, Y.R. Cao, S.J. He, W.K. Zhang, X.J. Wang, S.Y. Chen, and J.S. Zhang. 2009. The ethylene receptor ETR2 delays floral transition and affects starch accumulation in rice. Plant Cell 21:1473-1494. 